Iran Journal of Nursing (IJN)

Vol 32, No. 119, Aug 2019: 1- 12

\title{
Effect of Reminiscence on the Happiness the Retired Elderly Members of the Islamic Republic of Iran Army
}

\author{
Abbasali Sheykhi ${ }^{1}$, Ali Navidian ${ }^{2}$, Roghaieh Keykha ${ }^{3}$, Nasrin Rezaee ${ }^{4}$
}

\begin{abstract}
Background \& Aims: Aging is an inevitable biological process, which is associated with physical, psychological, and social changes. Studies have suggested that the retired elderly members of military forces have different life experiences than others, which are reflected in their wellbeing. These experiences may cause the loss of vitality and specifically happiness, which is a essential criterion of mental health. Reminiscence is considered to be a preventive and therapeutic intervention for the elderly, which affects various aspects of their social and mental health. Due to the aging population of Iran and the fact that the majority of the elderly are retired, the present study aimed to assess the impact of reminiscence on the happiness of the retired elderly members of the Islamic Republic of Iran Army (AJA).

Materials \& Methods: This quasi-experimental study was conducted in winter 2018 on 90 retired men aged more than 60 years, who referred to the retired AJA personnel center. The participants were divided into two groups of experimental and control (45 subjects per each). The participants were selected via simple random method and assigned to the experimental and control groups by drawing lots. The inclusion criteria were the minimum retirement duration of six months, age of 60-70 years (young-elderly), physical and mental health for participation (as stated by the family members), adequate hearing as reported by the individual, acquiring the minimum score of seven for the cognitive assessment in the abbreviated mental test (AMT) for the screening of cognitive disorders in the elderly, written consent for participation, and living with a spouse. The exclusion criteria were absence of more than one session in the reminiscence intervention, severe family crisis during the study (e.g., loss of a family member), and group intolerance. Considering 95\% confidence interval (CI) and 95\% test power, the sample size of 34 subjects was determined for each group. Each group was assigned 45 subjects to compensate for the possible data loss, and 90 individuals were selected as the sample population. The experimental group received six sessions of reminiscence twice a week, and the duration of each session was 45-60 minutes at the retired AJA personnel center of Zahedan, Iran. Each session was implemented for 5-8 participants, and each participant was provided an average of 5-7 minutes for each meeting. While the control group received no intervention, a reminiscence session was held for these individuals at the posttest. Data were collected using a self-report questionnaire, which consisted of three sections. The first section included the personal data of the elderly individuals on age, education level, retirement period, number of children, and postretirement employment. The second and third sections were the Oxford happiness questionnaire and AMT for the screening of cognitive disorders in the elderly. The questionnaires were completed on the first day before the intervention and two months after the reminiscence sessions at the posttest. Data analysis was performed in SPSS version 16 using descriptive statistics (frequency, percentage, mean, standard deviation, range) and inferential statistics (paired and independent t-test, Chi-square).

Results: The mean age of the participants in the experimental and control groups was 68 years, and all the subjects were married and had children. More than $57 \%$ of the subjects in the experimental group had a post-

1. MS Student in Psychiatric Nursing, School of Nursing and Midwifery, Zahedan University of Medical Sciences, Zahedan, Iran

2. Professor, Pregnancy Health Research Center, Department of Psychiatric Nursing, School of Nursing and Midwifery, Zahedan University of Medical Sciences, Zahedan, Iran

${ }^{3}$. Lecturer, Community Nursing Research Center, Department of Psychiatric Nursing, School of Nursing and Midwifery, Zahedan University of Medical Sciences, Zahedan, Iran

4. Assistant Professor, Community Nursing Research Center, Department of Psychiatric Nursing, School of Nursing and Midwifery, Zahedan University of Medical Sciences, Zahedan, Iran (Corresponding author) Tel:09153411705 Email: nasrin_rezaee2005@yahoo.com
\end{abstract}


retirement job, and $42 \%$ were unemployed after retirement. The mean score of happiness in the experimental group increased from $48.82 \pm 3.51$ to $56.51 \pm 6.14$ after the intervention. In addition, the mean score of happiness in the control group increased from $47.66 \pm 6.99$ to $49.68 \pm 7.96$ after the reminiscence sessions. The mean score of happiness in the experimental and control groups was $7.68 \pm 5.43$ and $2.02 \pm 6.70$, respectively. The independent t-test indicated a significant difference in the happiness score of the study groups after the intervention $(\mathrm{P}=0.0001)$, and the mean score range of happiness was considered significant in both groups $(\mathrm{P}=0.0001)$. Additionally, the paired t-test showed a significant difference in the mean score of happiness between the experimental $(\mathrm{P}=0.0001)$ and control groups $(\mathrm{P}=0.04)$ before and after the intervention.

Conclusion: This study confirmed the positive impact of group reminiscence therapy on the happiness of the retired elderly. Since the elderly are fond of expressing memories, it is possible to use the therapeutic aspects of reminiscence to promote their vitality and mental health. Reminiscence is an appealing, simple, and inexpensive intervention, which could be employed to reduce the anxiety and stress of the elderly in various communities. According to this study, the level of happiness increased in the control group regardless of the intervention, suggesting that attention to the elderly replaced their passive state with an active and happy disposition. Therefore, such interventions are recommended in nursing homes and geriatric wards to create a congenial atmosphere. One of the limitations of this study was the physical health condition of the elderly, which occasionally caused their later arrival at the intervention sessions. In some cases, the relatives who were interested in accompanying their elders were allowed to attend the sessions as well. Another limitation was the experiences of war as the majority of the subjects tended to express unsettling memories (e.g., martyrdom of their friends), which created a gloomy atmosphere in the sessions. Therefore, it is advised that further investigations in this regard address the gradual impact and persistence of memories on the elderly in the form of longitudinal studies.

Keywords: Reminiscence, Happiness, Elderly, Retirement

\section{Conflict of Interest: No}

How to Cite: Sheykhi A, Navidian A, Keykha R, Rezaee N. Effect of Reminiscence on the Happiness the Retired Elderly Members of the Islamic Republic of Iran Army. Iran Journal of Nursing. 2019; 32(119):1-12.

Received: 4 May 2019

Accepted: 3 Aug 2019 


\title{
تأثير خاطره كويى بر شادكامى سالمندان بازنشسته ارتش جمهورى اسلامى ايران
}

\author{
عباسعلى شيخى '، على نويديان '، رقيه كيخاّ، نسرين رضائى
}

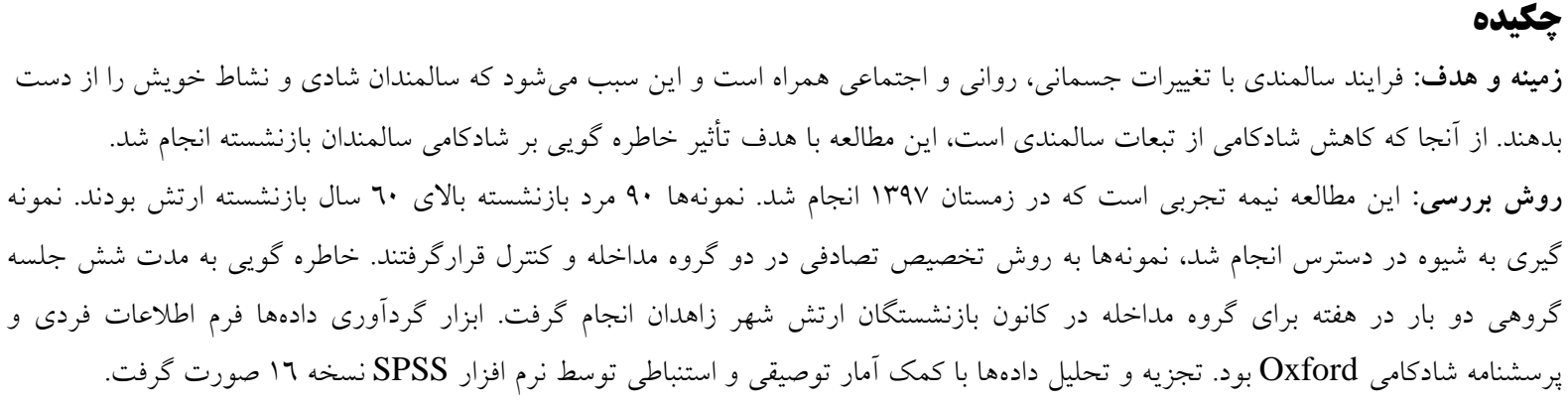

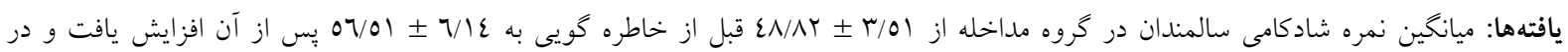
كروه كترل از T/99

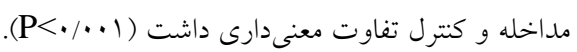

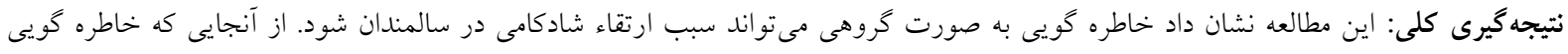

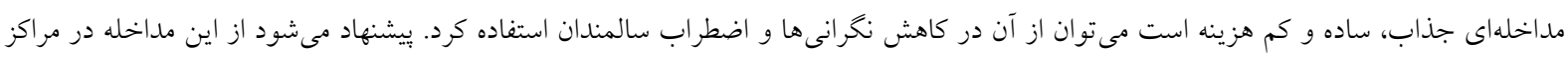
نغهدارى از سالمندان و بخش سالمندان براى ايجاد جوى مفرح استفاده شود.

كليد وازهها: خاطره گويى، شادكامى، سالمند، بازنشستخى

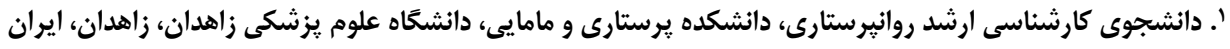

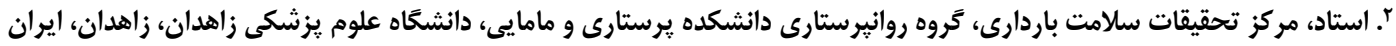

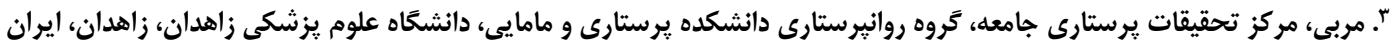

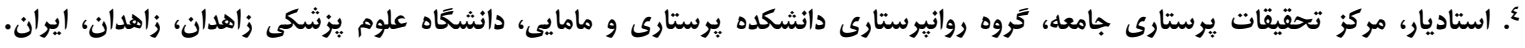


نقشى است كه سالهاى متمادى داثته و به قالب جديدى در آمدن است. سالمندى به همراه بازنشستخى با فقدان

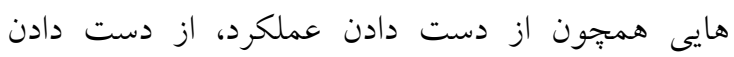

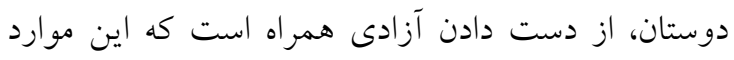

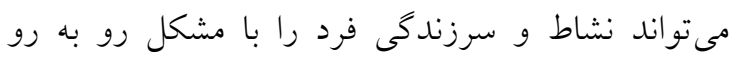
سازد (ع) با اين وجود مطالعات نشان داده است كه سالمندان بازنشسته نيروهاى نظامى (كهنه سربازان) تجارب متفاوتى

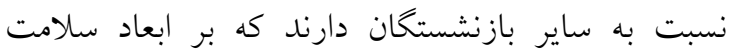

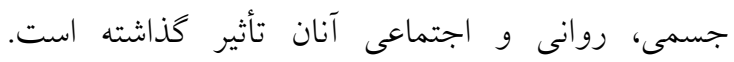
بطورى كه مطالعهاى كه بر روى بيش از ل.م نفر از

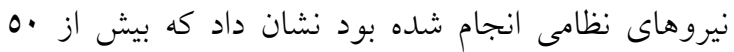
درصد آنان از سلامت روان (در ابعاد افسردكى، اضطراب

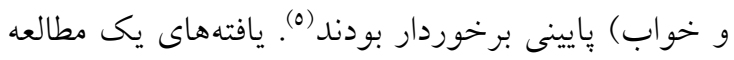
كوهورت كه به بررسى عوامل مؤثر بر سلامت روان كهنه

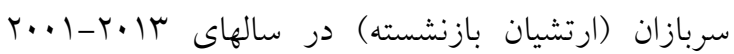

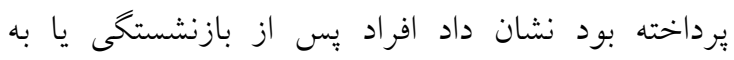

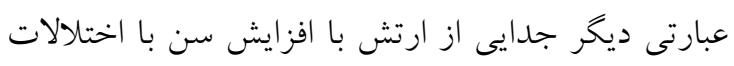

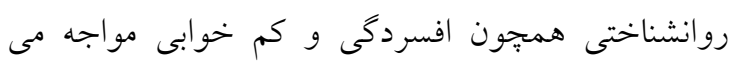

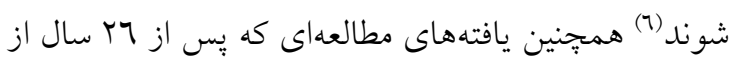

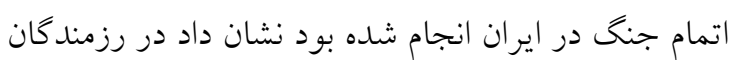

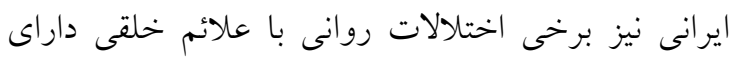

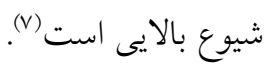
به نظر مىرسد طيف وسيعى از بازنشستخان، نتوانستهاند خود را با وضعيت سالمندى و بازنشستخى ساز كار نمايند و در نتيجه دجار انواع مشكلات روانى شدند. شادكامى بانى يكى از ملاكهاى مهم سلامت روان است. مطالعات نشان داده است كه نشاط با افزايش سن كاهش مى ميابد (ه^). همجنين يافتهاى مطالعهاى نشان داد كه بيش از نود

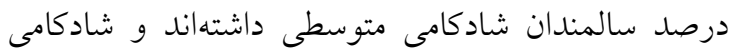
آنها با وضعيت اقتصادى ارتباط داشته است (9). به عبارتى در سالمندان بازنشسته از شادكامى نيز با كاهش درآمد كاسته مىشود. از سويى ديخر كرايش سالمندان به ركود و سكون، باعث مىشود كه شادى، نشاط و احساس

\section{مقلمهه}

سالمندى يك فرايند بيولوزيكى اجتناب نايذير است كه

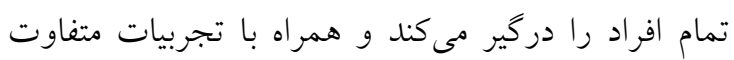

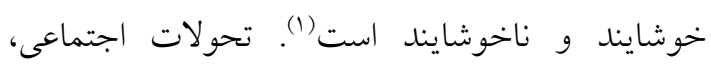

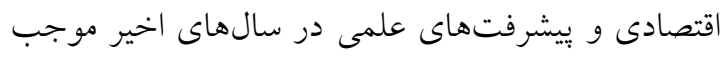

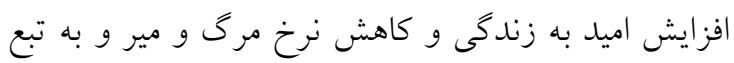
آن افزايش جشمخير جمعيت سالمندان شده است. تخمين زده مىشود كه جمعيت سالمندان در جهان تا •ع سال

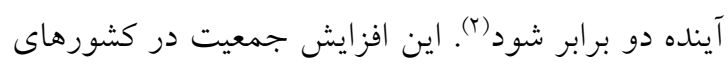

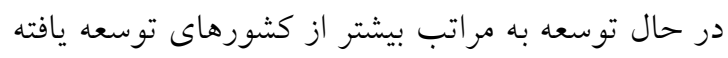

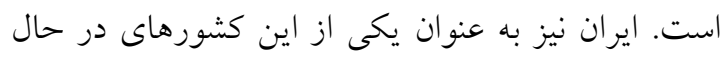

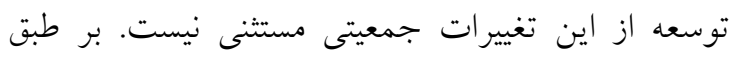

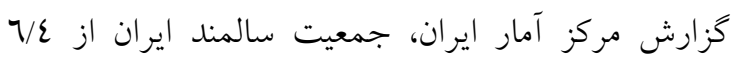

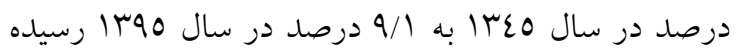
است (r). با توجه به افزايش سريع تعداد سالمندان، مسأله بهداشت، سلامت و تأمين آسايش و رفاه آنان در جامعه هر روز ابعاد تازه و كستردهترى ييدا مى كند. در هر حال فرايند سالمندى با تغييرات جسمانى كوناكون، تغييرات

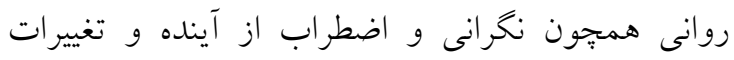

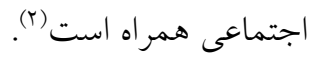
در كنار سالمندى متغير ديخرى به نام بازنشستخى وجود المد

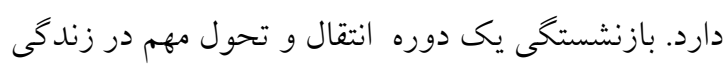

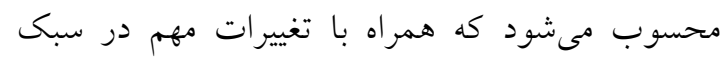

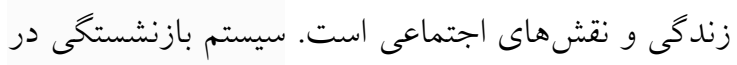
كشورها متفاوت است و فاكتورهاى متعددى در بازنشستخى نقش دارند در كشور ايران براى اكثر مشاغل

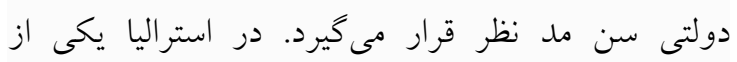

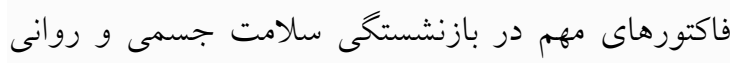

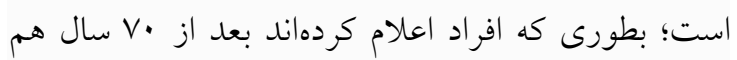
كار خواهند كرد. سن بازنشستخى قانونى در كشور نروز

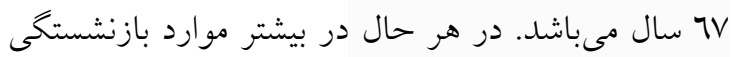
به دنبال ورود به سالمندى اتفاق مىافتد و سازمان بهداشت جهانى شروع سالمندى را 70-7.7 سال گزارش كرده است. در واقع بازنشستكى به معناى جدا شدن فرد از 
تواند به عنوان مراقبت روتين در سالمندان با علائم

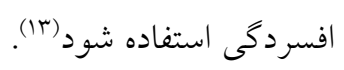

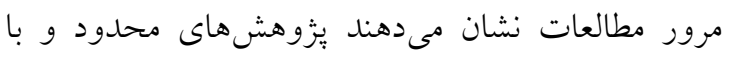

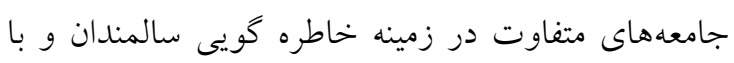

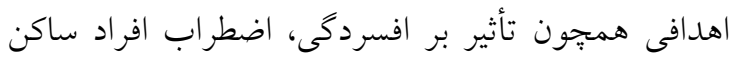
در خانه سالمندان و يا معلمان انجام شده است (rا--(ا،ب). علاوه بر اين بسيارى از يزوهشها در حوزه سالمندى به

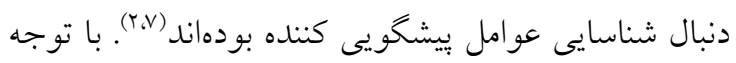

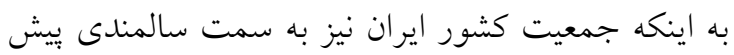

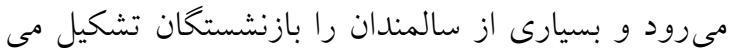
دهند و سالمندان با مشكلات متعلد روانشناختى مواجهند كه منجر به غمخينى و ناراحتى آنان مىشود، اين مطالعه با هدف تعيين تأثير خاطره كويى بر شادكامى سالمندان بازنشسته ارتش جمهورى اسلامى ايران انجام شد. سمان.

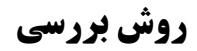

يُزوهش حاضر يك مطالعه نيمه تجربى است كه در

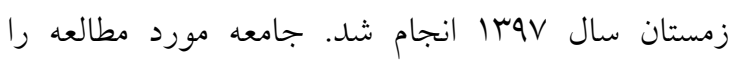

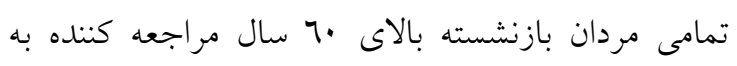

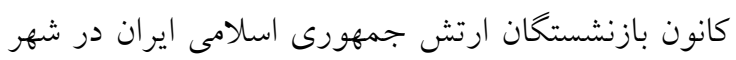

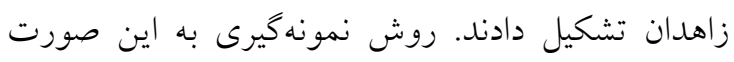

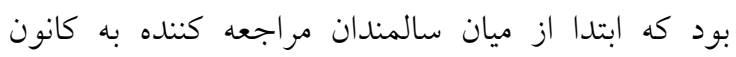
بازنشستخان كه داراى معيارهاى ورود به مطالعه بودند، نمونهها به شيوه در دسترس انتخاب شدند سبس نمونهها

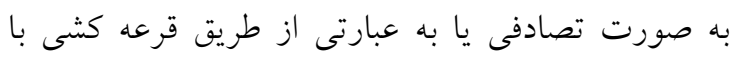
كارت كه به تعداد افراد كروه مداخله و كنترل تهيه شده بود و با انتخاب كارت مورد نظر در كروه مداخله و كنترل قرار مى گرفتند. معيارهاى ورود به مطالعه عبارت بودند از

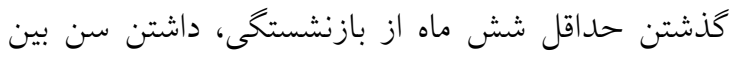
00-70 سال (سالمندان جوان)، برخوردارى نسبى از سلامت جسمى و روانى جهت شركت در گروه (بنا به كفته خانواده فرد)، برخوردارى از شنوايى قابل قبول بنا

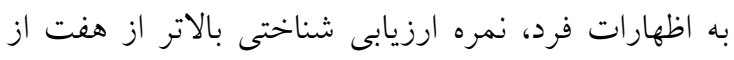

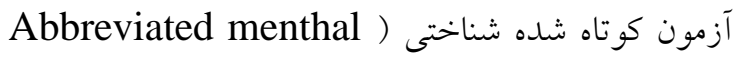

سودمندى خويش را از دست دهند. شادكامى مولد انرزى،

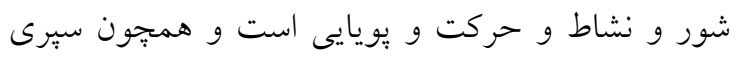

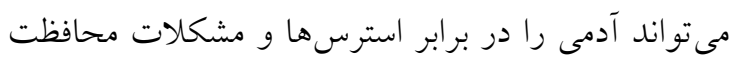
كند و سلامت جسمى و روانى فرد را تضمين كند (r). با فيا توجه به مزاياى شادكامى، همه جوامع خواستار شادى،

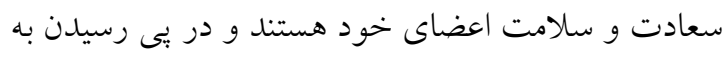

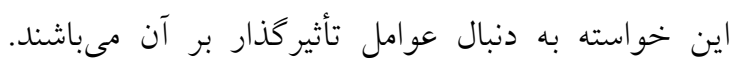
نتايج مطالعهاى در خانه سالمندان كهريزك نشان داد ديدن فيلم به صورت كروهى منجر به ارتقاء شادكامى در

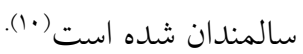
مداخلات روانشناختى متنوعى براى سالمندان داراى مشكلات روانى مانند اضطراب، افسردگى، و انزواى ملى ملى

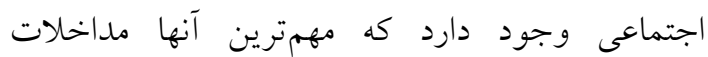
روانشناختى از جمله شناخت درمانى، روايت درمانى،

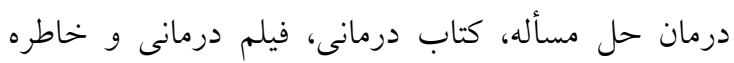

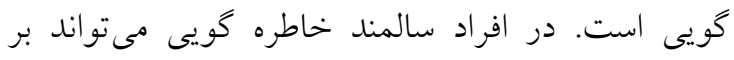
ابعاد مختلف سلامت اجتماعى و روانى تأثير كذار باشد.

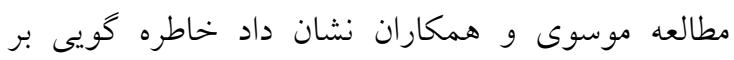

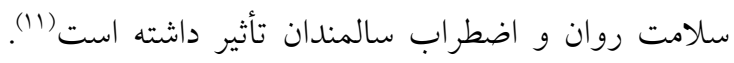
خاطره كويى مداخلهاى است كه اغلب براى افراد سالمند

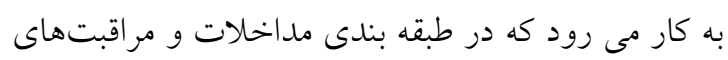

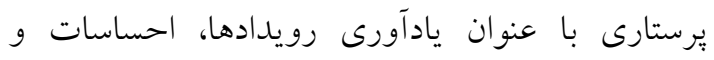

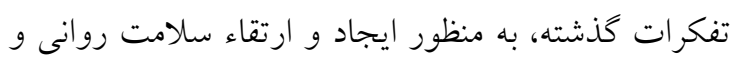
اجتماعى با ايجاد جوى شاد و فعال به كار مىرود. خاطره

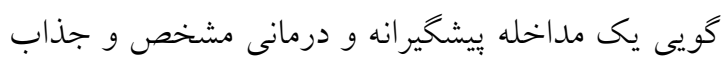

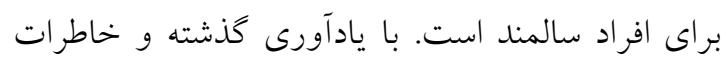

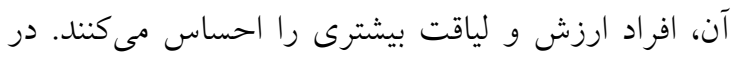

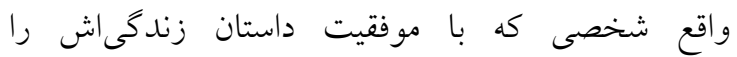

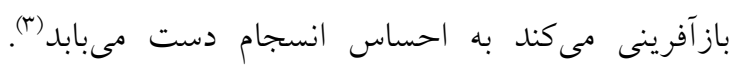
خاطره گويى بر افزايش شادكامى و كاهش افسردكى تأثير

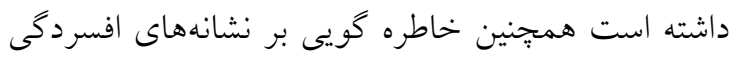

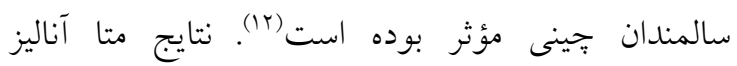

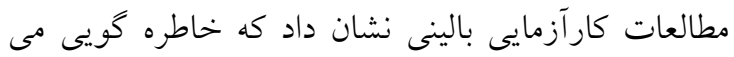


تهيه شده است. اين آزمون اولين بار توسط Hedkinson دارد. ياسخ درست به هر سئوال نمره ا و ياسخ غلط نمره صفر خواهد كرفت و نمره كل جمع پاسخهاى صحيح

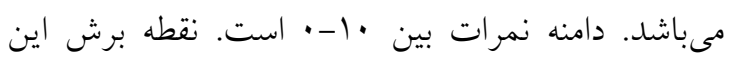

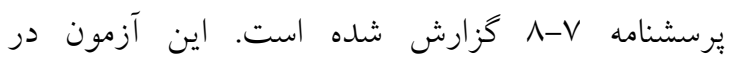
كشورهاى مختلف روانسنجى شده است. در كشور

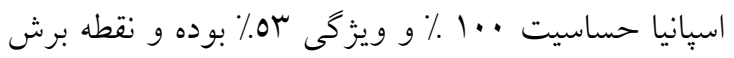
بين V-1 را نشان داده است. در كشور ايران نيز روانسنجى انجام شده است و نقطه برش V كزارش شده

مداخله به شيوه برگزارى جلسات خاطره گويى انجام

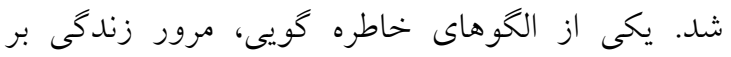

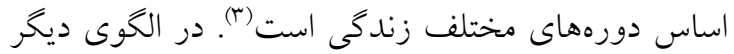

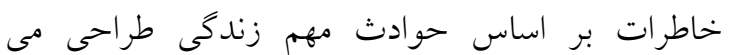

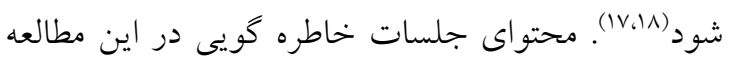

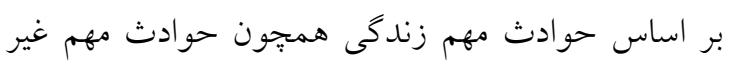

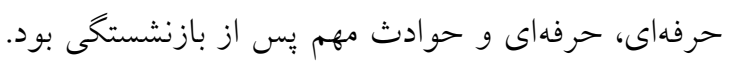

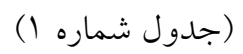
بعد از كسب مجوز از كميته اخلاق معاونت تحقيقات و و

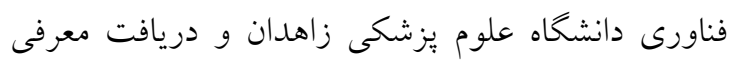

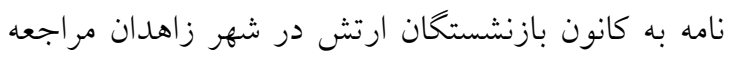

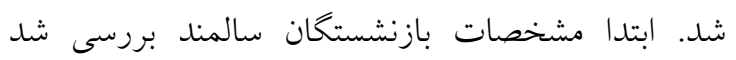

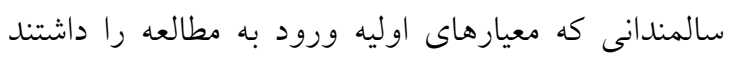
مشخص شدند و شماره تماس آنها از پِرونده آنان

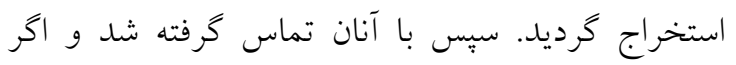
ساير معيارهاى ورود را نيز دارا بودند و نيز تمايل به له فئس شركت در انجام مطالعه را داشتند به عنوان نمونهاى مورد يزوهش انتخاب شدند. سبس اين افراد به صورت تخصيص تصادفى در گروههاى كنترل و مداخله قرار

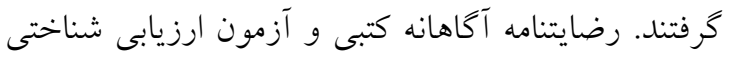

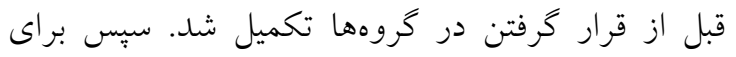

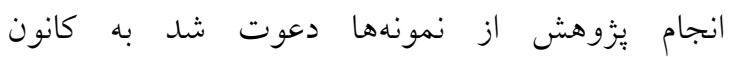

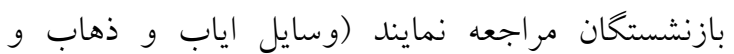

test رضايت براى شركت در مطالعه، و نيز زندگى در

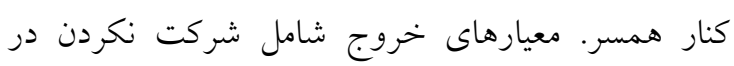

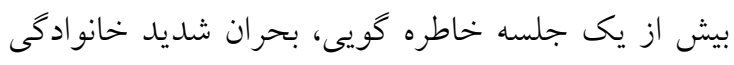

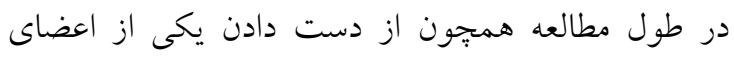

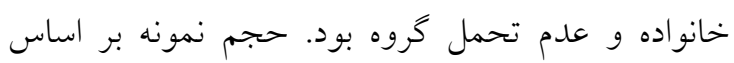

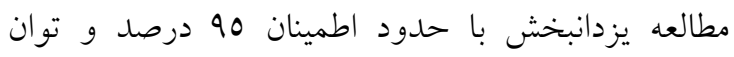

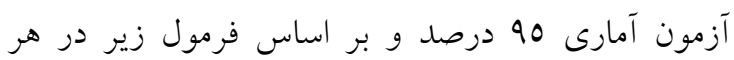

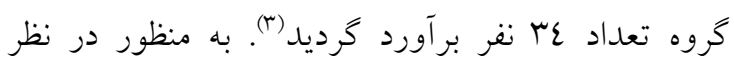

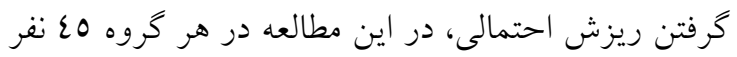
و در مجموع •9 نفر حجم نمونه تعيين شد.

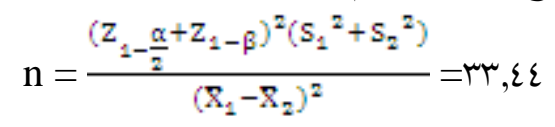

ابزار جمع آورى اطلاعات در اين مطالعه برسشنامهاى

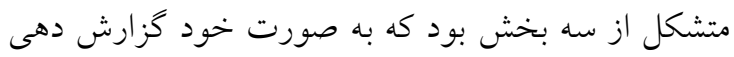
تكميل شد. بخش اول اطلاعات فردى سالمند شامل سن، ميزان تحصيلات، مدت بازنشستخى، تعداد فرزندان و

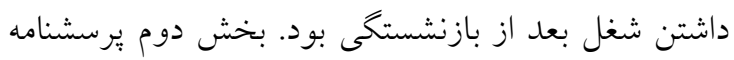
شادكامى Oxford و بخش سوم آزمون كوتاه شده

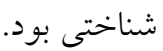
برسشنامه شادكامى (Oxford happiness index): اين برسش نامه توسط Argyle و Lu دu سر سال 1919

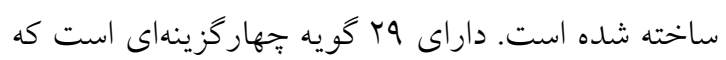

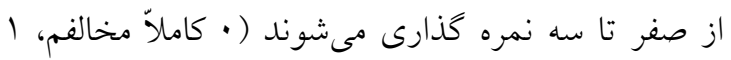

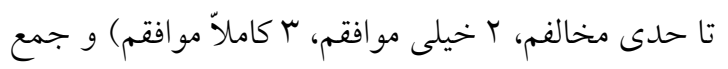
نمره گزينهها، نمره كل مقياس را تشكيل مى مدهد كه كه

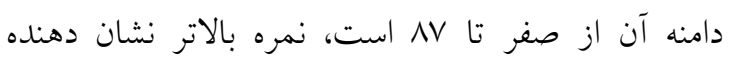

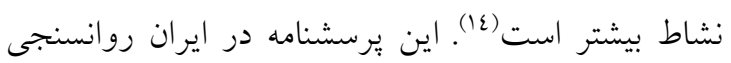
شده است. بررسى همسانى درونى مواد يُرسشنامه نشان

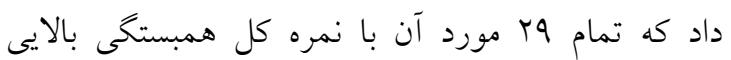

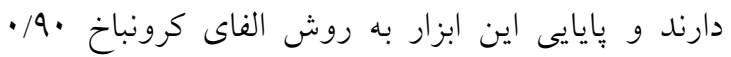

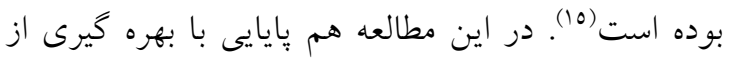
ضريب آلفاى كرونباخ، 10/ • محاسبه شد. آزمون كوتاه شده شناختى(AMT): آزمون كوتاه شده شناختى براى غربالكرى اختلالات شناختى در سالمندان 
يرستارى در تمامى جلسات جهت بررسى و مراقبت

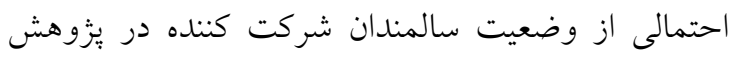
حضور داشت. محل بركزارى جلسات كانون بازنشستخان ارتش يا يكى از مراكز درمانى ارتش در شهر زاهد بران بوده.

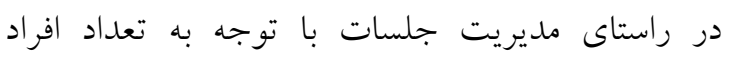
شركت كننده در جلسات به طور متوسط V-0 دقيقه براى

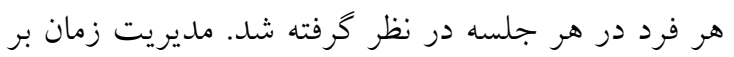

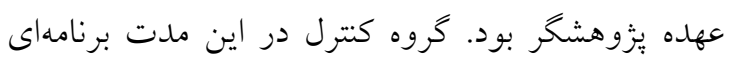

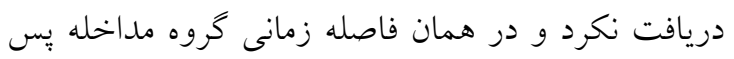

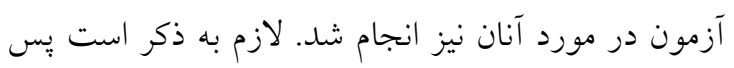

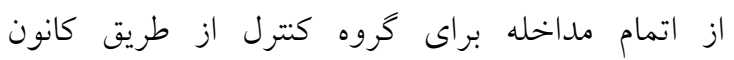

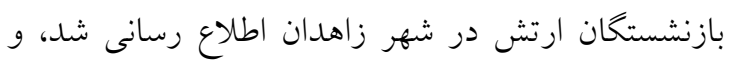
يك جلسه خاطره گويى براى گروه كتترل نيز برگزار شد.
امكانات اوليه مثل دسترسى آسان به سرويس بهداشتى

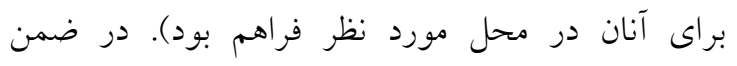

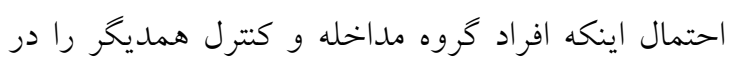

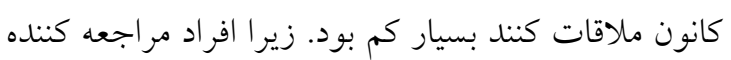

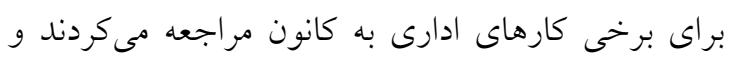

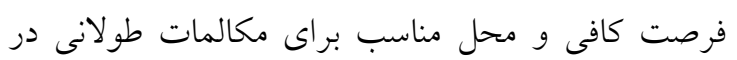
فضاى كانون وجود نداشت.

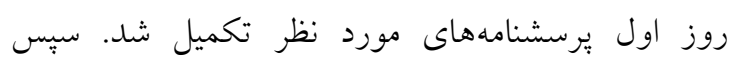

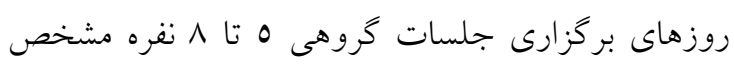
شد. جلسات خاطره كويى شش جلسه دو روز در هفته و

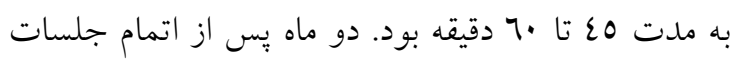

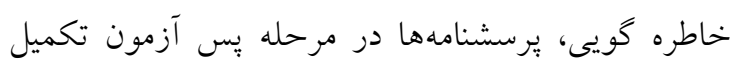

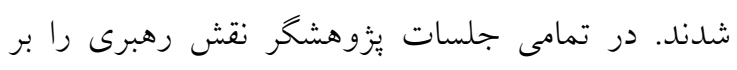

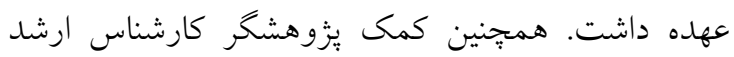

جدول شماره (: ساختارجلسات تَروهى خاطره تَويى

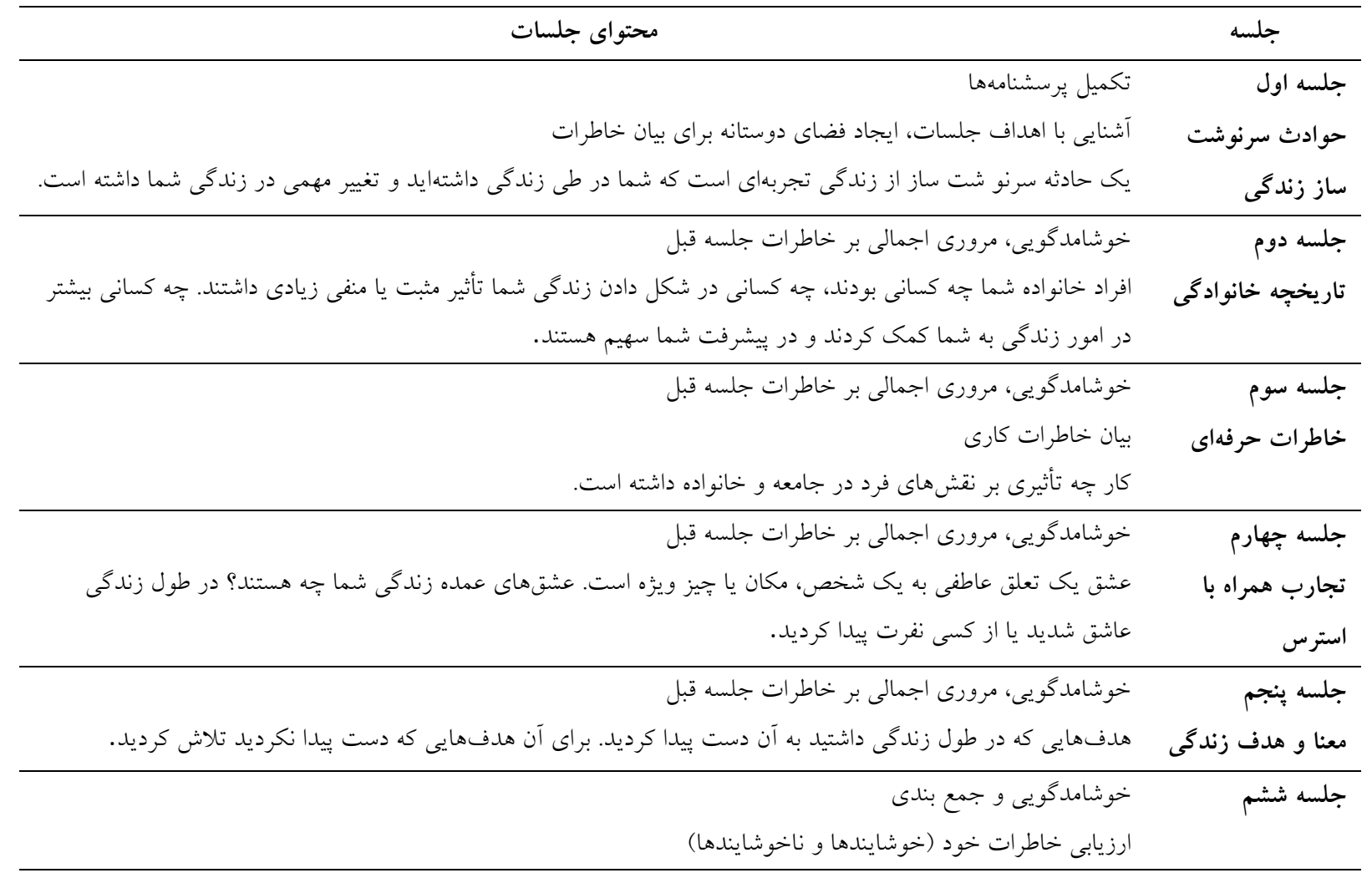


ملاحظات اخلاقى از جمله رضايت آكاهانه كتبى، اطمينان

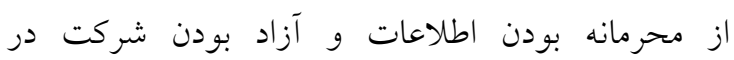

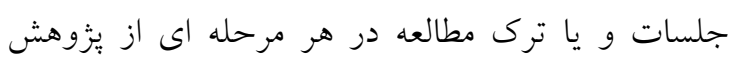
مورد توجه قرار گرفتند.

\section{إفته ها}

ميانگين سن در گروه مداخله و كنترل ل شال بود. همه Oازنشستخان متأهل و داراى فرزند بودند. بيش از درصد نمونهها در گروه مداخله داراى شغل يّ از بازنشستخى بودند و rاع درصد آنان يس از بازنشستخى شغل دوم اختيار نكرده بودند. مشخصات جمعيت شناختى نمونهها در جدول شماره Y ارائه شده است.
داده ها توسط نرم افزار SPSS نسخه 17 مورد تجزيه و تحليل قرار كرفتند. ابتدا به كمك آمار توصيفى درصد

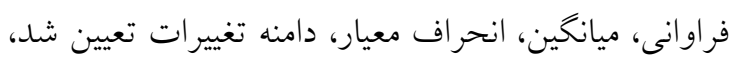
در ادامه از آمار استنباطى در مقايسه ميانخينهاى قبل و بعد در هر گروه از آزمون تى زوجى، مقايسه ميانخينهاى بين گروهها از آزمون تى مستقل و مقايسه متغيرهاى كيفى از آزمون كاى دو استفاده شد. در ابتدا با استفاده از آزمون كلموكراف اسييرنوف مشخص شد دادهها از توزيع نرمال برخوردارند. بنابر اين از آزمونهاى پِارامتريك استفاده شد.

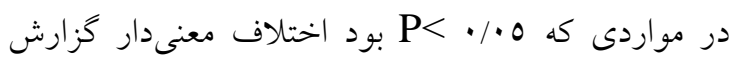
شد. اين مطالعه در دانشخاه علوم يزشكى زاهدان با كد اخلاق 379

جدول شماره r: مشخصات جمعيت شناختى سالمندان بازنشسته در تَروه مداخله و كنترل

\begin{tabular}{|c|c|c|c|c|}
\hline نتيجه آزمون & 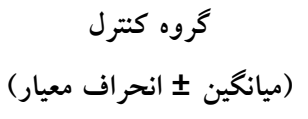 & 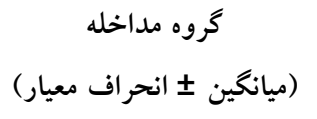 & ت تغير & \\
\hline $\begin{array}{c}*_{\mathrm{t}=}=/ \mathrm{r} \\
\mathrm{df}=\wedge \Lambda \\
\mathrm{P}=\cdot / \Sigma V \mathrm{~T}\end{array}$ & \rceil$/ /\urcorner \varepsilon \pm \varepsilon / 7$. & $\eta / \cdot r \pm r / \varepsilon\rceil$ & \multicolumn{2}{|c|}{ سن } \\
\hline $\begin{array}{c}* \mathrm{t}=\cdot / 77 \\
\mathrm{df}=\wedge \Lambda \\
\mathrm{P}=\cdot / 01 \mathrm{r}\end{array}$ & $r / O r \pm 1 / r T$ & $r / r O \pm I / r T$ & \multicolumn{2}{|c|}{ تعداد فرزندان } \\
\hline$* * \chi^{2}=1 / 97$ & فراو انى (درصد) & فراو انى (درصد) & \multirow{4}{*}{\multicolumn{2}{|c|}{ فييلم }} \\
\hline$d f=r$ & $(10 / 7) 17$ & $(Y \varepsilon / \varepsilon) 11$ & & \\
\hline $\mathrm{P}=\cdot / \mu V r$ & $(\Psi \backslash /) \backslash \varepsilon$ & $(Y \wedge / q) \mid r$ & & \\
\hline & 10 & $(\Sigma T / V) Y I$ & & \\
\hline$* * \chi^{2}=r / I V$ & $(\varepsilon Y / T) 19$ & $(O V / \Lambda) Y Y$ & دارد & \multirow{2}{*}{ بعد از بازنشستخى اشتغال } \\
\hline $\begin{array}{c}\mathrm{df}=1 \\
\mathrm{P}=\cdot / \backslash \varepsilon \varepsilon\end{array}$ & $(O V / A) Y T$ & $(\varepsilon r / T) 19$ & ن ندارد & \\
\hline
\end{tabular}

V/M و در گروه كنترل • T/N آزمون آمارى تى مستقل نشان داد كه ميانخين نمره شادكامى يّ از مداخله خاطره گويى در دو گروه مداخله

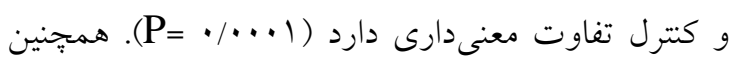
ميانخين تغييرات نمره شادكامى در دو كروه سالمندان

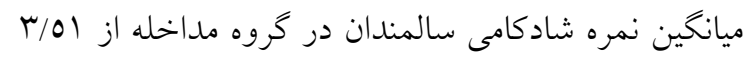
IN/NT \pm و در گروه كنترل از 7/99 به V/97

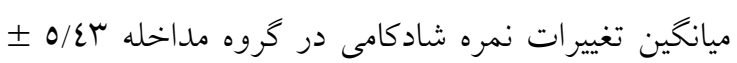




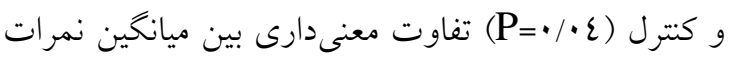

شادكامى قبل و بعد وجود دارد (جدول شماره س).

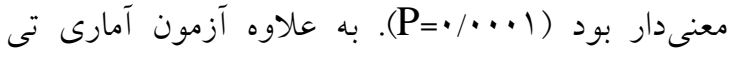

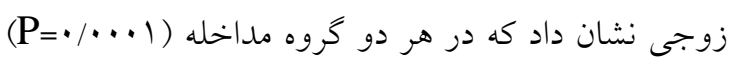

جدول شماره سا: مقايسه ميانغين نمره شادكامى سالمندان قبل و بعد از مداخله خاطره تَويى در كَروه مداخله و كنترل

\begin{tabular}{|c|c|c|c|c|}
\hline \multirow[t]{2}{*}{ آزمون تى زوج } & تغييرات & بِ از مداخله & قبل از مداخله & \multirow[t]{2}{*}{ زمان } \\
\hline & انحراف معيار 土 ميانكين & انحر اف معيار 土 ميانگين & انحراف معيار 土 ميانكين & \\
\hline$t=9 / 29$ & \multirow[t]{3}{*}{$V / T \perp \pm 0 / \varepsilon r$} & \multirow[t]{3}{*}{$07 / 01 \pm 7 / 1 \varepsilon$} & \multirow[t]{3}{*}{$\sum N / \Lambda Y \pm r / 01$} & \multirow[t]{3}{*}{ مداخله } \\
\hline $\mathrm{df}=\varepsilon \varepsilon$ & & & & \\
\hline $\mathrm{P}=\cdot / \cdots \cdot \mid$ & & & & \\
\hline$t=r / . r$ & \multirow[t]{3}{*}{$r / \cdot r \pm T / V}$. & \multirow[t]{3}{*}{$9 / 71 \pm V / 97$} & \multirow[t]{3}{*}{$\varepsilon V / 77 \pm 7 / 99$} & \multirow[t]{3}{*}{ كترل } \\
\hline$d f=\varepsilon \varepsilon$ & & & & \\
\hline \multirow[t]{4}{*}{$\mathrm{P}=\cdot \cdot \cdot \varepsilon r$} & & & & \\
\hline & $t=\varepsilon / \varepsilon$. & $t=\varepsilon / 0 \varepsilon$ & $t=\cdot / 99$ & \multirow[t]{3}{*}{ آزمون تى مستقل } \\
\hline & $\mathrm{df}=\wedge \Lambda$ & $\mathrm{df}=\wedge \wedge$ & $\mathrm{df}=\wedge \wedge$ & \\
\hline & $\mathrm{P}=\cdot / \ldots$, & $\mathrm{P}=\cdot / \cdots \cdot \mid$ & $\mathrm{P}=\cdot / r r$ & \\
\hline
\end{tabular}

بود(10). در بسيارى از مطالعات به تأثير خاطره گويى بر

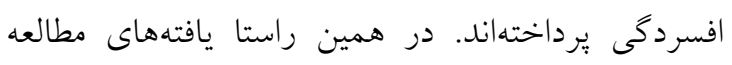

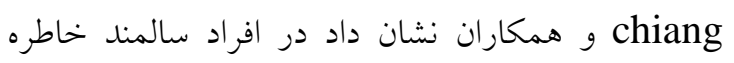

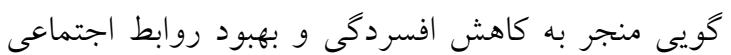

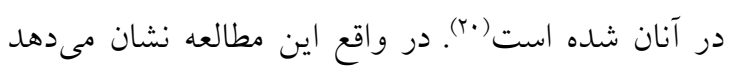

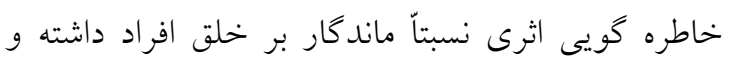

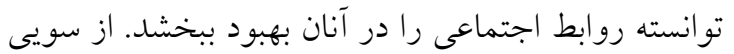
ديخر يافتهاى مطالعهاى نشان داد شادكامى در افراد

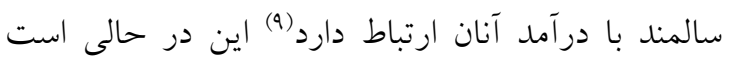
مطالعه حاضر نشان داد در سالمندان و بازنشستخان كه از از درآمد بايين ترى برخوردارند خاطره كويى توانسته شرايط شاد و لذت بخشى را براى آنان فراهم آورد. همجنين مطالعه Teng و همكاران كه به تأثير خاطره

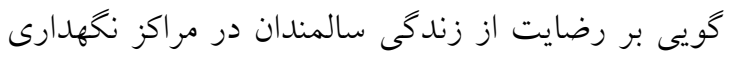

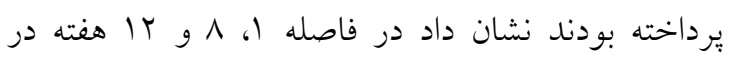
كروه مداخله در هر سه زمان رضايت از زندكى ارتقاء

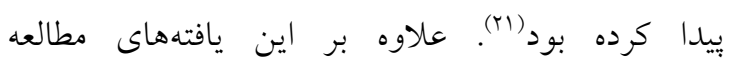

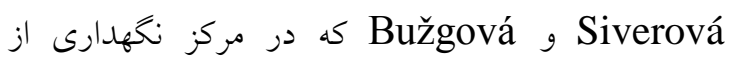
سالمندان انجام شده بود نشان داد خاطره گويى تأثير مثبت بر كيفيت زندكى و نكرش به بيرى داشته و علائم

\section{بحث و نتيجه}

يزوهش حاضر به منظور تأثير خاطره كويى بر شادكامى نيجى سالمندان بازنشسته ارتش شهر زاهدان انجام شد. يافتهـها

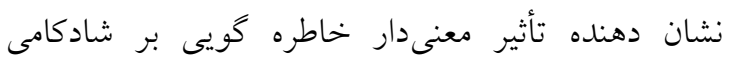
سالمندان مطالعه بود كه نشان دهنده اثر بخشى مداخدله

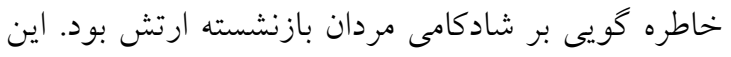

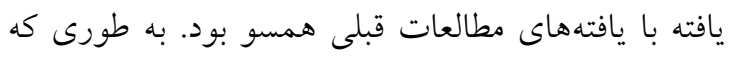

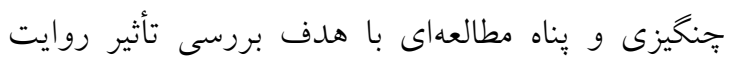
درمانى كروهى بر شادكامى سالمندان شهر تبريز انجام

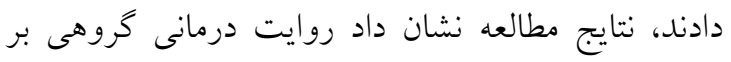

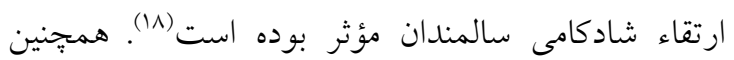

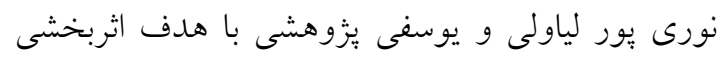
خاطره يردازى گروهى بر شادكامى سالمندان انجام دادند.

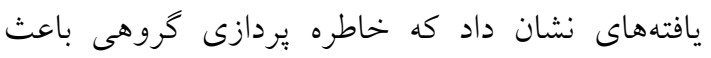

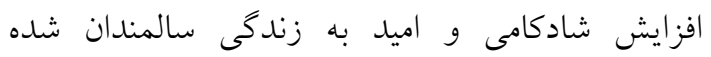

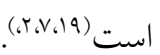
از آنجايى كه ويزّى هاى افراد شادكام بر عكس افراد

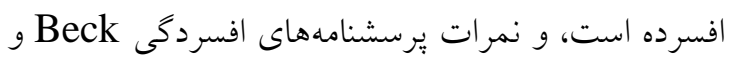
شادكامى Oxford مؤيد اين نكته مىباشند به عبارتى برسئس

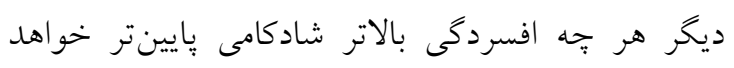


دوستان) قرار مى گيرند از سلامت اجتماعى و باطبع

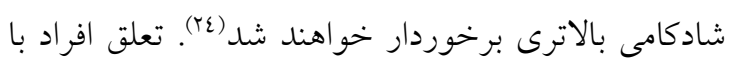

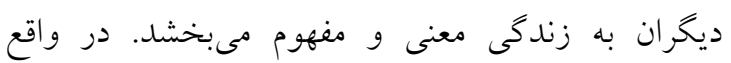

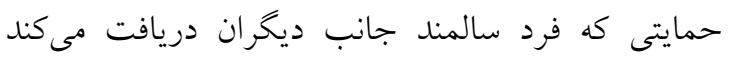
باعث مىشود او احساس كند كه به جامعه و اطرافيانش تعلق دارد و داراى شأن و ارزش است.

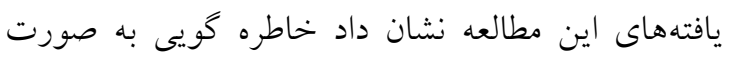
كروهى مى تواند سبب ارتقاء شادكامى در سالمندان شود.

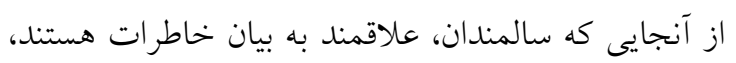

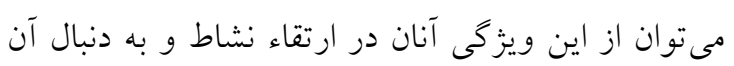

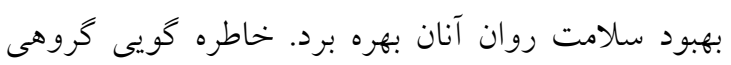

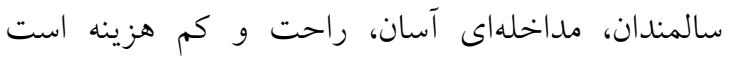

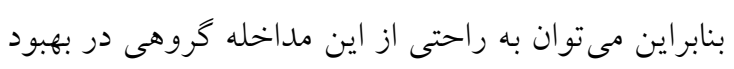

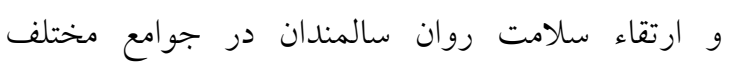

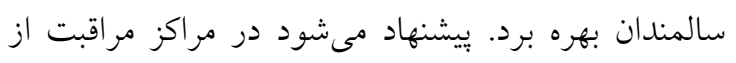

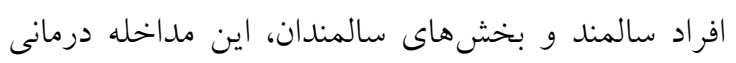
كه به راحتى توسط برستاران قابل اجرا است بركزار شود.

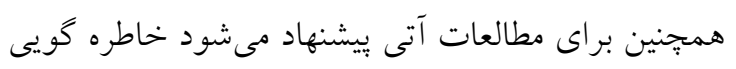
در سالمندان بصورت مطالعات طولى انجام شود تا تأثير و ماندكارى آن در طى زمان مشخص شود.

تعارض منافع: نويسندكان هيج كونه تعارض منافعى را

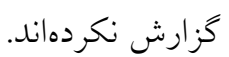

\section{تقدير و تشكر}

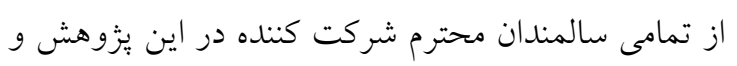

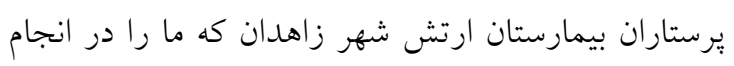

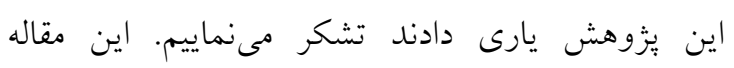

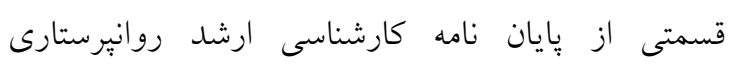

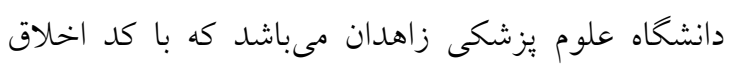

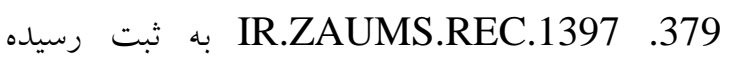

افسردگى را در سالمندان كاهش داده است(Yr). اين يافتهها نشان مى دهند خاطره گويى از علاقه مندىهاى سالمندان

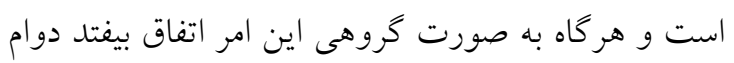

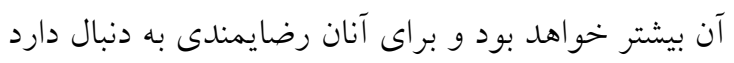

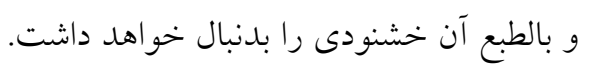

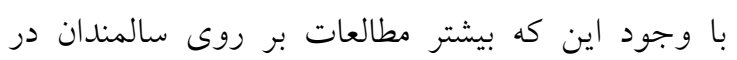

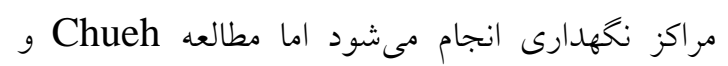
Chang با هدف تأثير خاطره كويى بر روى علائم

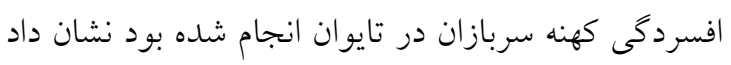

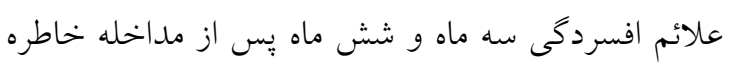

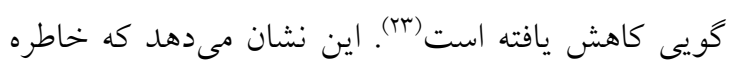

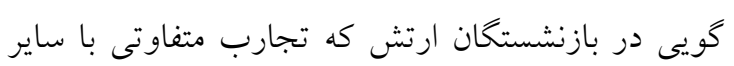

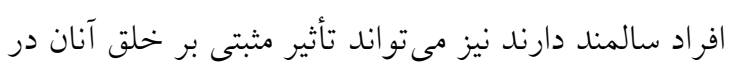
مدت زمان طولانى ترى داشته باشد.

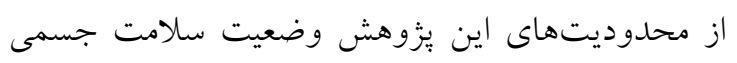

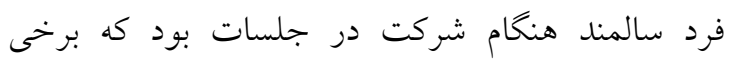
جلسات با تأخير به كلاس مىرسيدند و در برخى موارد

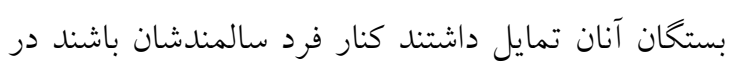

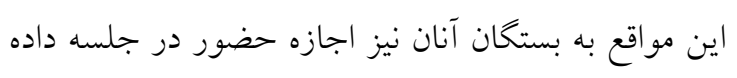

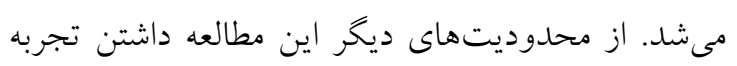

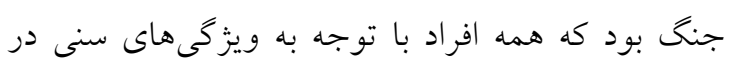

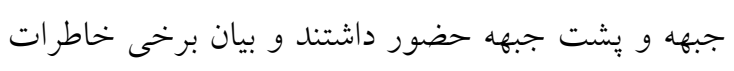
جنگ مثل شهيد شدن دوستان فضاى ناراحت كنندهاى را بوجود مى آورد. لازم است به اين مطلب اشاره شود كه نتايج در كروه كنترل هم معنى دار بود؛ بدين معنى كه در كروه كنترل نيز

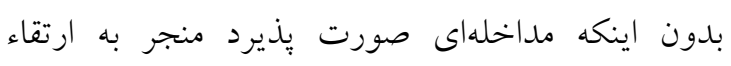

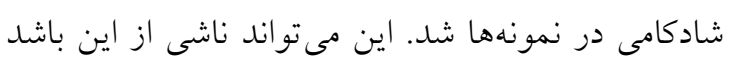

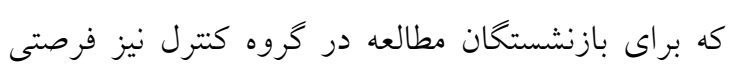

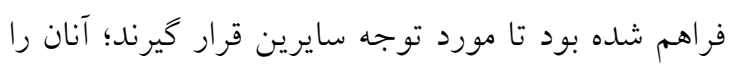

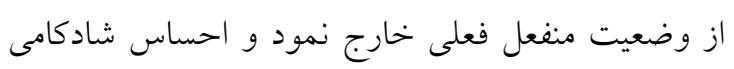

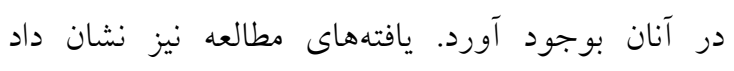
سالمندانى كه مورد حمايت سايرين (به غير از خانواده و 


\section{References}

1- Fakari FR, Hashemi MA, Fakari FR. A Qualitative research: Postmenopausal women's experiences of abuse. Procedia Soc Behav Sci. 2013;82:57-60.

2- Elias SM, Neville C, Scott T. The effectiveness of group reminiscence therapy for loneliness, anxiety and depression in older adults in long-term care: a systematic review. Geriatric Nursing. 2015;36(5):372-80.

3- Yazdanbakhsh K. Effects of Life Review on Social Adjustment of Retirees'elderly Persons. Journal of Aging Psychology. 2016;1(3):179-85. [Persian]

4- Keshavarz-Afshar H, Jahan-Bakhshi Z, Anisi J, Azad-Marzabadi E, Ghahvehchi-Hosseini F. The Determination of Mental Health among Military Retired Forces based on Organizational and Humanistic Variables. Journal of Military Medicine. 2016;18(2):191-6. [Persian]

5- Rajabi S, Narimani M, Basari A. Evaluation and comparison of mental health statues a policemen and military personnel. Journal of Military Psychology. 2013;4(13):32-43. [Persian]

6- Armenta RF, Rush T, LeardMann CA, Millegan J, Cooper A, Hoge CW. Factors associated with persistent posttraumatic stress disorder among US military service members and veterans. $B M C$ psychiatry. 2018;18(1):48.

7- yousefi Z, sharifi $\mathrm{K}$, tagharrobi $\mathrm{Z}$, akbari $\mathrm{H}$. The effect of group reminiscence on happiness of the elderly. Evidence Based Care. 2014;4(3):33-46. [Persian]

8- Rahnejat A, Dabagi P, Rabiei M, Taghva A, Valipoor H, Donyavi V. Prevalence of PostTraumatic Stress Disorder Caused by War in Veterans. Iran J War Public Health. 2017;9(1):1523. [Persian]

9- Almasi M, Mahmoudiani S, Jafari M. Factors associated with feelings of happiness among the elderly. Iran Journal of Nursing. 2015;27(92):23-32. [Persian]

10- Hosseini FA, Khodabakhshi-koolaee A, Taghvaee D. Effectiveness of group film therapy on happiness and quality of life among elderly adults of Kahrizak nursing home. Journal of Health Literacy. 2016;1(2):109-17.

11- Musavi M, Mohammadian S, Mohammadinezhad B. The effect of group integrative reminiscence therapy on mental health among older women living in Iranian nursing homes. Nursing Open. 2017;4(4):303-9. [Persian]

12- Huang HC, Chen YT, Chen PY, Hu SH, Liu F, Kuo YL, Chiu HY. Reminiscence therapy improves cognitive functions and reduces depressive symptoms in elderly people with dementia: A meta-analysis of randomized controlled trials. J Am Med Dir Assoc. 2015 1;16(12):1087-94.

13- Song D, Shen Q, Xu TZ, Sun QH. Effects of group reminiscence on elderly depression: A metaanalysis. Int J Nurs Sci. 2014;1(4):416-22.

14- Argyle M, Martin M, Crossland J. Happiness as a function of personality and social encounters. Recent advances in social psychology: An international perspective. 1989:189-203.

15- Alipoor A, Noorbala AA. A preliminary evaluation of the validity and reliability of the Oxford happiness questionnaire in students in the universities of Tehran. Iranian Journal of Psychiatry and Clinical Psychology. 1999;5(1):55-66. [Persian]

16- Bakhtiyari F, Foroughan M, Fakhrzadeh H, Nazari N, Najafi B, Alizadeh M, Arzaghi M, Sharifi F, Shoaee S, Mostafa Q. Validation of the persian version of Abbreviated Mental Test (AMT) in elderly residents of Kahrizak charity foundation. Iranian Journal of Diabetes and Metabolism. 2014;13(6):487-94. [Persian]

17- 17-Abdollahzadeh H, khabbazi M. Effectiveness Of Integrative Reminiscence On Health anxiety, Death Depression And Perceived Stress In Elderly. Psychology Health. 2017;6(22): 101-4. [Persian]

18- Changizi F, Panahali A. Effectiveness of group narrative therapy on life expectancy and happiness of the elderly in Tabriz. Journal of educational sciences. 2016, 9 (34):63-76. [Persian]

19- Nooripour R, Alikhani M, Hosseinian S, Soheilizadeh S, Mohammadifar MA. The Effectiveness of Group Reminiscence on Happiness and Life Expectancy in Elderly. Journal of Aging Psychology. 2015;1(3):147-56. [Persian]

20- Chiang KJ, Chu H, Chang HJ, Chung MH, Chen CH, Chiou HY, Chou KR. The effects of reminiscence therapy on psychological well-being, depression, and loneliness among the institutionalized aged. Int J Geriatr Psychiatry. 2010;25(4):380-8. 
21- Ching-Teng Y, Chia-Ju L, Hsiu-Yueh L. Effects of structured group reminiscence therapy on the life satisfaction of institutionalized older adults in Taiwan. Social work in health care. 2018 14;57(8):674-87.

22- Siverová J, Bužgová R. The effect of reminiscence therapy on quality of life, attitudes to ageing, and depressive symptoms in institutionalized elderly adults with cognitive impairment: A quasi-experimental study. Int J Mental Health Nurses. 2018;27(5):1430-9.

23- Chueh KH, Chang TY. Effectiveness of group reminiscence therapy for depressive symptoms in male veterans: 6-month follow-up. Int J Geriatr Psychiatry. 2014;29(4):377-83.

24- Tajmazinani AA, Larijani M. A Study of Factors Influencing Social Exclusion of the Elderly in Varamin City. Journal of Applied Sociology (1735-000X). 2015 Sep 1;59(3). 